\title{
Sintering Kinetics of Plasma-Sprayed Zirconia TBCs
}

A. Cipitria, I.O. Golosnoy, and T.W. Clyne

(Submitted March 14, 2007; in revised form May 9, 2007)

\begin{abstract}
The sintering of free-standing plasma sprayed TBCs has been modeled, based on variational principles of free energy minimization and comparisons are made with experimental results. Predictions of throughthickness shrinkage and changing pore surface area are compared with the experimental data obtained by dilatometry and BET analysis, respectively. The sensitivity of the predictions to initial pore architecture and material properties is assessed. The model can be used to predict the evolution of the contact area between overlying splats. This is in turn related to the through-thickness thermal conductivity, using a previously developed analytical model (I.O. Golosnoy, et al. J. Therm. Spray Technol., 2005, 14(2), p 205-214).
\end{abstract}

Keywords diffusion, modeling, plasma-sprayed thermal barrier coatings, sintering, variational principle

\section{Introduction}

Thermal barrier coatings (TBCs) usually comprise a metallic bond coat (e.g., MCrAlY), which protects the base metal against oxidation and corrosion and improves the adhesion of the top coat. The top coat is commonly based on zirconia stabilized by $8 \mathrm{wt} \%$ yttria $\left(\mathrm{ZrO}_{2}\right.$ 8 wt. $\% \mathrm{Y}_{2} \mathrm{O}_{3}$ ) and is produced by air plasma spray (APS) or electron beam physical vapor deposition (EB-PVD). Coating thickness is usually in the range of $100-500 \mu \mathrm{m}$, creating a temperature drop of $\sim 50-200{ }^{\circ} \mathrm{C}$. TBCs are used in aero-engine and power generation gas turbine components subjected to high temperature, such as blades and nozzle guide vanes. Currently sought increases in turbine entry temperature are dependent on improvements in the efficiency and reliability of TBCs.

Air plasma spray coatings contain interlamellar pores, globular voids and intrasplat microcracks. These are partly responsible for the low thermal conductivity $\left(k \sim 1 \mathrm{~W} \mathrm{~m}^{-1} \mathrm{~K}^{-1}\right)$ and low global Young's modulus $(E \sim 25 \mathrm{GPa})$ of these coatings, the latter being beneficial in reducing the stresses arising from differential thermal contraction. Under service conditions, however, TBCs are

This article is an invited paper selected from presentations at the 2007 International Thermal Spray Conference and has been expanded from the original presentation. It is simultaneously published in Global Coating Solutions, Proceedings of the 2007 International Thermal Spray Conference, Beijing, China, May 1416, 2007, Basil R. Marple, Margaret M. Hyland, Yuk-Chiu Lau, Chang-Jiu Li, Rogerio S. Lima, and Ghislain Montavon, Ed., ASM International, Materials Park, OH, 2007.

A. Cipitria, I.O. Golosnoy, and T.W. Clyne, Department of Materials Science and Metallurgy, University of Cambridge, Cambridge, UK. Contact e-mail: ac472@cam.ac.uk.

exposed to high temperatures for extended periods, leading to sintering effects. Healing of microcracks, improved intersplat bonding, and grain growth can raise both the thermal conductivity and Young's modulus, degrading both the insulation offered and the thermo-mechanical stability of the TBC. In this article, a model is presented for the sintering of plasma-sprayed (PS) TBCs.

\begin{tabular}{|ll|}
\hline & \multicolumn{1}{c|}{ Nomenclature } \\
\hline$A_{\mathrm{s}}$ & Total free surface area, $\mathrm{m}^{2}$ \\
$A_{\mathrm{gb}}$ & Total grain boundary area, $\mathrm{m}^{2}$ \\
$D_{0}$ & Diffusivity, $\mathrm{m}^{2} \mathrm{~s}^{-1}$ \\
$E$ & Young's modulus, Pa \\
$\bar{G}$ & Free energy per unit volume, $\mathrm{J} \mathrm{m}^{-3}$ \\
$h$ & Height from the centre of the bridge to the centre \\
& of the splat, $\mathrm{m}$ \\
$J$ & Volumetric flux per unit depth, $\mathrm{m}^{3} \mathrm{~m}^{-1} \mathrm{~s}^{-1}$ \\
$k$ & Thermal conductivity, W $\mathrm{m}^{-1} \mathrm{~K}^{-1}$ \\
$k_{\mathrm{B}}$ & Boltzman constant, $\mathrm{J}$ atom \\
$M$ & Atomic mobility, $\mathrm{K}^{2} \mathrm{~J}^{-1} \mathrm{~s}^{-1}$ \\
$N_{\mathrm{s}}$ & Number of grains within a splat \\
$Q$ & Activation energy, $\mathrm{J}$ mol \\
$r_{\mathrm{b}}$ & Radius of contact between splats, $\mathrm{m}$ \\
$r_{\mathrm{g}}$ & Grain size (side of hexagonal prism), $\mathrm{m}$ \\
$r_{\mathrm{s}}$ & Radius of the splat, $\mathrm{m}$ \\
$R$ & Universal gas constant, $\mathrm{J}$ mol \\
$T$ & Absolute temperature, $\mathrm{K}$
\end{tabular}




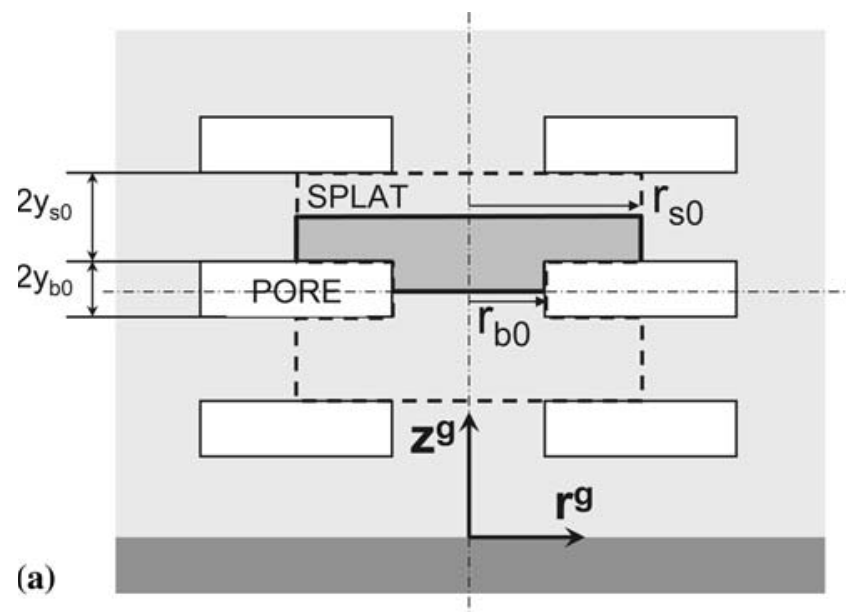

(b)

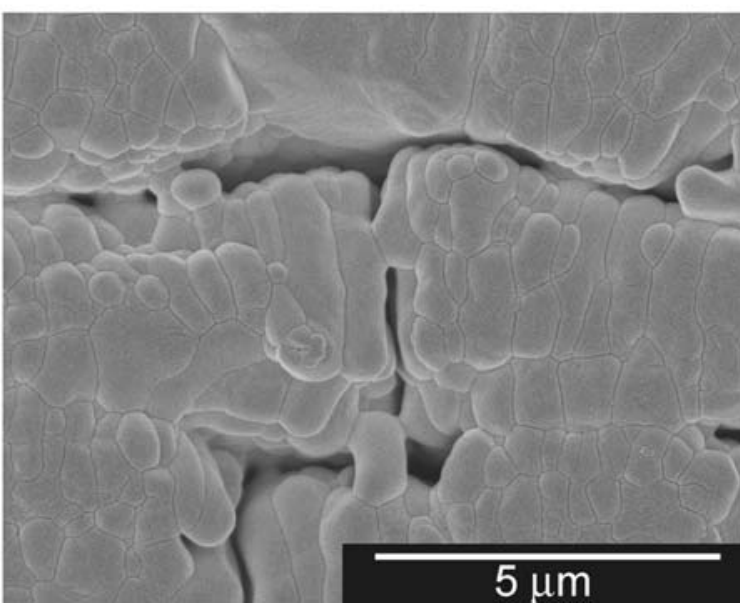

Fig. 1 Model (a) and SEM micrograph (b) of PS TBC

\section{General Framework}

The microstructure of PS TBCs is represented as cylindrical disks (splats) of radius $r_{\mathrm{s} 0}$ and height $2 y_{\mathrm{s} 0}$, with a cylindrical bridge contact of radius $r_{\mathrm{b} 0}$ and open pore dimension $2 y_{\mathrm{b} 0}$ (see Fig. 1a). Due to symmetry, the volume of the modeled unit cell corresponds to half-height of the splat, $y_{\mathrm{s} 0}$, and half-height of the pore, $y_{\mathrm{b} 0}$. The splats are composed of columnar grains (see Fig. 1b), modeled as hexagonal prisms of side $r_{\mathrm{g} 0}$ (see Fig. 2). A horizontal grain boundary (inter-splat contact area) is located at the mid-height of the bridge. The geometry is based on cylindrical coordinates $\left(r^{\mathrm{g}}, z^{\mathrm{g}}\right)$. The through-thickness direction is along $z^{\mathrm{g}}$, with the origin located at the interface with the substrate. The temperature distribution is taken to be isothermal at any given value of $z^{\mathrm{g}}$, but can vary in the through-thickness direction. However, in the current work, the temperature is assumed uniform within the modeled domain. Modeled domains are assumed to tesselate in a hexagonal in-plane array and to stack on top of each other in the through-thickness direction. The space between the close-packed array of cylinders (comprising about $8 \%$ of the total volume), which is outside the modeled domain, is taken to represent porosity

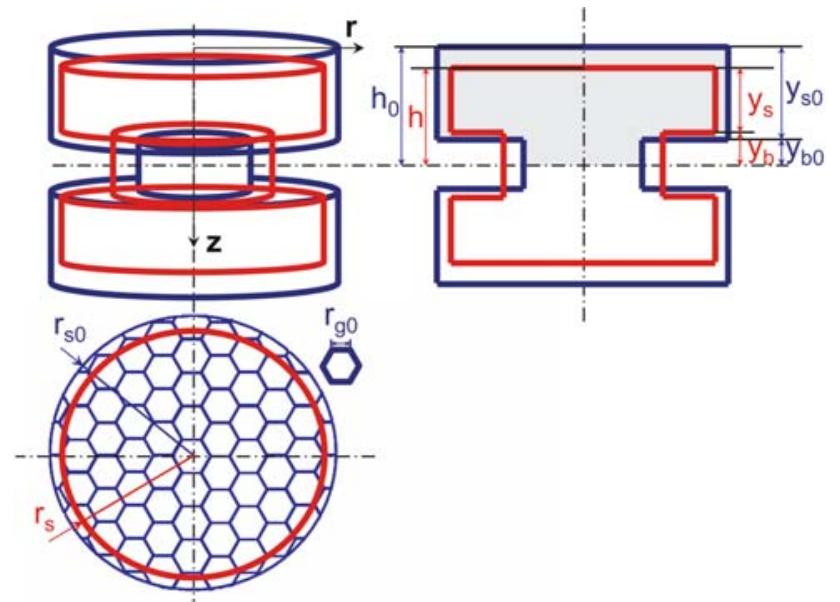

Fig. 2 Perspective, plan, and elevation views of the initial (blue) and later (red) dimensions of the modeled domain

inaccessible to the influence of sintering phenomena. In practice, some relatively large scale, equiaxed porosity is commonly present, at approximately this level.

As sintering proceeds (Fig. 2), surface diffusion contributes to spherodization of pores, resulting in an increase of the open pore dimension, $y_{\mathrm{b}}$, and a decrease of the splat height, $y_{\mathrm{s}}$. Grain boundary diffusion, on the other hand, causes the coating to shrink in the through-thickness and in-plane directions, reducing the height from the centre of the bridge to the centre of the splat, $h$, and the splat radius, $r_{\mathrm{s}}$. Grain growth due to grain boundary migration is not incorporated in the modeling presented here. However, grain boundary diffusion along the vertical grains redistributes the material and changes the grain size, $r_{\mathrm{g}}$, and thus, the splat radius, $r_{\mathrm{s}}$. The number of grains within each splat, $N_{\mathrm{s}}$, is assumed to remain constant.

Microstructural evolution is described by the changing values of the three independent parameters: $h, y_{\mathrm{s}}$ and $r_{\mathrm{s}}$. By mass conservation, $y_{\mathrm{b}}$ and $r_{\mathrm{b}}$ can be expressed as a function of these:

$y_{\mathrm{b}}\left(h, y_{\mathrm{s}}, r_{\mathrm{s}}\right)=h-y_{\mathrm{s}}$

$r_{\mathrm{b}}\left(h, y_{\mathrm{s}}, r_{\mathrm{s}}\right)=\left[\frac{r_{\mathrm{b} 0}^{2} y_{\mathrm{b} 0}+r_{\mathrm{s} 0}^{2} y_{\mathrm{s} 0}-r_{\mathrm{s}}^{2} y_{\mathrm{s}}}{h-y_{\mathrm{s}}}\right]^{1 / 2}$

The volume of material corresponding to a unit cell is:

$\mathrm{Vol}=\pi\left(r_{\mathrm{s} 0}^{2} y_{\mathrm{s} 0}+r_{\mathrm{b} 0}^{2} y_{\mathrm{b} 0}\right)$

\subsection{The Variational Principle}

The variational principle has been applied to various diffusion related physical problems, such as growth of cavities and crack propagation (Ref 1,2$)$, creep deformation (Ref 2,3), grain growth (Ref 4), morphological evolution of electronic thin films, due to surface diffusion, elastic energy and electric current (Ref 5), diffusion multicomponent systems (Ref 6), or solid-state sintering (Ref 2, 7-13). The formulation of the solid-state sintering 
problem, using the variational principle, is described elsewhere (Ref 14-17).

At a given temperature, if the atoms have enough mobility, they diffuse along the free surfaces, grain boundaries, and through the lattice, so as to reduce the total free energy. Energy is dissipated during mass transport, because atoms must overcome internal friction forces. A balance is established between the rates of free energy reduction $\dot{G}$ and energy dissipation $\Psi$. The system progresses in the way to keep the function $\Pi=\dot{G}+\Psi$ at minimum. It is shown that the minimum occurs at a stationary point, i.e.,:

$\delta \bar{\Pi}=\delta(\dot{\bar{G}}+\bar{\Psi})=0$

The current model represents a free-standing coating, with fully interconnected porosity. Thus, there are no contributions to the free energy from either the stored elastic strain energy or the pressure acting on free surfaces. The free energy per unit volume $\bar{G}$ is given by:

$$
\begin{aligned}
\bar{G}\left(h, y_{\mathrm{s}}, r_{\mathrm{s}}\right)= & \frac{1}{\mathrm{Vol}}\left[\int_{A_{\mathrm{s}}} \gamma_{\mathrm{s}} d A_{\mathrm{s}}+\int_{A_{\mathrm{gb}}} \gamma_{\mathrm{gb}} d A_{\mathrm{gb}}\right] \\
= & \frac{1}{\mathrm{Vol}_{\mathrm{ol}}}\left[\gamma_{\mathrm{s}}\left(\pi\left(r_{\mathrm{s}}^{2}-r_{\mathrm{b}}^{2}\right)+2 \pi r_{\mathrm{b}} y_{\mathrm{b}}\right)\right. \\
& \left.+\gamma_{\mathrm{gb}}\left(\frac{1}{2} \pi r_{\mathrm{b}}^{2}+\sqrt{2 \sqrt{3} \pi N_{\mathrm{s}}} r_{\mathrm{s}}\left(y_{\mathrm{s}}+\frac{r_{\mathrm{b}}^{2}}{r_{\mathrm{s}}^{2}} y_{\mathrm{b}}\right)\right)\right]
\end{aligned}
$$

where $\gamma_{\mathrm{s}}$ and $\gamma_{\mathrm{gb}}$ are the specific surface and grain boundary energies, respectively, and $\mathrm{A}_{\mathrm{s}}$ and $\mathrm{A}_{\mathrm{gb}}$, the total free surface and grain boundary areas. The factor of $1 / 2$ arises, because the energy of the horizontal grain boundary, at the contact bridge, is divided between the top and bottom parts. Assumed paths of material diffusion are along grain boundaries and free surfaces. Lattice diffusion and grain growth are not treated in the version of the model presented here. The rate of energy dissipation per unit volume $\bar{\Psi}$ is:

$$
\begin{aligned}
& \bar{\Psi}\left(\dot{h}, \dot{y}_{\mathrm{s}}, \dot{r}_{\mathrm{s}}\right) \\
& =\frac{1}{\mathrm{Vol}}\left[\int_{A_{\mathrm{s}}} \frac{1}{2 M_{\mathrm{s}} \Omega \delta_{\mathrm{s}}} J_{\mathrm{s}} J_{\mathrm{s}} d A_{\mathrm{s}}+\int_{A_{\mathrm{gb}}} \frac{1}{2 M_{\mathrm{gb}} \Omega \delta_{\mathrm{gb}}} J_{\mathrm{gb}} J_{\mathrm{gb}} d A_{\mathrm{gb}}\right]
\end{aligned}
$$

where $\Omega$ is the atomic volume; $J$ is the volumetric flux per unit depth, $\delta$ is the layer thickness through which diffusion takes place and $M$ is the atomic mobility. The subscripts $\mathrm{gb}$ and $\mathrm{s}$ refer to grain boundary and free surface, respectively. The atomic mobility is given by:

$M=\frac{D_{0} \exp (-Q / R T)}{k_{\mathrm{B}} T}$

where $D_{0}$ is the diffusivity, $Q$ is the activation energy, $k_{\mathrm{B}}$ is the Boltzman constant, $R$ is the universal gas constant and $T$ is the absolute temperature.
Estimation of $\bar{\Psi}$ requires the calculation of fluxes along grain boundaries and free surfaces. In the study, all diffusion fluxes are assumed to be one dimensional, i.e., along surfaces and grain boundaries. Therefore, matter conservation is satisfied by relating the flux along an interface, to the displacement rate of that interface. As diffusion takes place along an interface, the material is deposited on, or removed from a particular part of the surface, resulting in a migration of the interface with a velocity $v_{\perp}$. Matter conservation requires that:

$\nabla \cdot J+v_{\perp}=q$

(Eq 8)

where $q$ represents additional sources or sinks for material.

Figure 3 depicts material fluxes along the interfaces, displacement rate of those interfaces and the existence of additional sources or sinks of material. Grain boundary diffusion flux along the vertical grain boundaries, $J_{\mathrm{gb}-\mathrm{V}}$, results in material removal from the grains and transports it along the vertical surfaces of the grains. In the model, every grain is assumed to be identical. This means that any change in the grain size, $r_{\mathrm{g}}$, is proportional to the splat radius, $r_{\mathrm{s}}$ (see $\mathrm{Eq} 9$ ), since the number of grains within each splat, $N_{\mathrm{s}}$, is assumed to be constant. There are no additional sources of material, hence $q$ is equal to zero.

$\sqrt{3} \dot{r}_{\mathrm{g}}=\sqrt{3} \sqrt{2 \pi / 3 \sqrt{3} N_{\mathrm{s}}} \dot{r}_{\mathrm{s}}$

The material that flows via grain boundary diffusion along the vertical grain boundaries, $J_{\mathrm{gb}-\mathrm{V}}$, accumulates on the interlamellar pore surface $\left(\dot{\mathrm{y}}_{\mathrm{s}}\left(\dot{\boldsymbol{r}}_{\mathrm{s}}\right)\right)$ and on the grain boundary on the contact bridge among splats $\left(\dot{\mathrm{h}}\left(\dot{r}_{\mathrm{s}}\right)\right)$. Matter conservation dictates:

$\pi r_{\mathrm{s}}^{2} y_{\mathrm{s}}=\mathrm{const}$

$\pi r_{\mathrm{b}}^{2}\left(h-y_{\mathrm{s}}\right)=\mathrm{const}$

Moreover, uniform shrinkage of the splat and the contact bridge is assumed, if only this diffusion mechanism is involved:

$\frac{r_{\mathrm{b}}}{r_{\mathrm{s}}}=\mathrm{const}$

Differentiating with time, the relations between the changes in grain size, $r_{\mathrm{g}}$, or splat radius, $r_{\mathrm{s}}$, and the fluxes

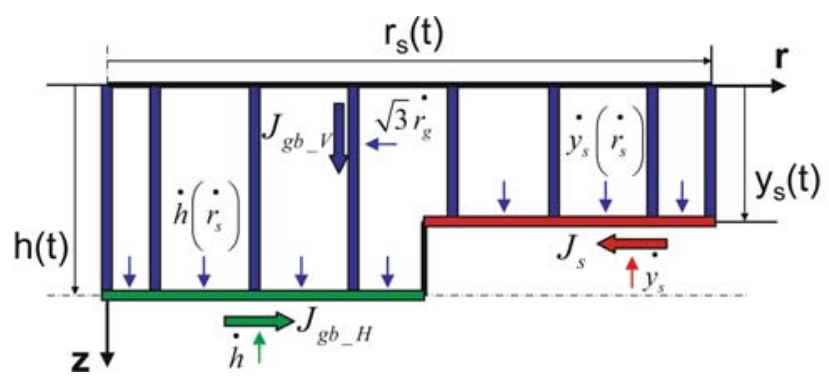

Fig. 3 Schematic depiction of the diffusion paths along interfaces and the migration velocities of interfaces 
to the surface and to the grain boundary, on the contact bridge between splats, are obtained.

$\dot{y}_{\mathrm{s}}\left(\dot{r}_{\mathrm{s}}\right)=-\frac{2 y_{\mathrm{s}}}{r_{\mathrm{s}}} \dot{r}_{\mathrm{s}}$

$\dot{h}\left(\dot{r}_{\mathrm{s}}\right)=-\frac{2 h}{r_{\mathrm{s}}} \dot{r}_{\mathrm{s}}$

The flux along the $r$ coordinate is divided into two regions: grain boundary diffusion along the horizontal grain boundary, $J_{\mathrm{gb}_{-} \mathrm{H}}\left(r=\left[0, r_{\mathrm{b}}\right]\right)$ and surface diffusion along the pore free surface, $J_{\mathrm{s}}\left(r=\left[r_{\mathrm{b}}, r_{\mathrm{s}}\right]\right)$. The former, with a displacement rate of the interface $\dot{h}$, has a source of additional material coming from the vertical grain boundaries $\dot{h}\left(\dot{r}_{\mathrm{s}}\right)=-2 h \dot{r}_{\mathrm{s}} / r_{\mathrm{s}}$. The latter, with a displacement rate of the interface $\dot{y}_{\mathrm{s}}$, has a source of additional material coming from the vertical grain boundaries $\dot{y}_{\mathrm{s}}\left(\dot{\boldsymbol{r}}_{\mathrm{s}}\right)=-2 y_{\mathrm{s}} \dot{r}_{\mathrm{s}} / r_{\mathrm{s}}$.

Migration velocities of the interfaces are assumed uniform along the interface (this is a result of assumed changes in pore architecture). Fluxes can thus be expressed:

$J_{\mathrm{gb} \_\mathrm{V}}(z)=-\sqrt{\frac{2 \pi}{\sqrt{3} N_{\mathrm{s}}}} \dot{\mathrm{r}}_{\mathrm{s}} z$

$J_{\mathrm{gb} \_\mathrm{H}}(r)=-\frac{r}{2}\left(\frac{2 h}{r_{\mathrm{s}}} \dot{r}_{\mathrm{s}}+\dot{h}\right) \quad r=\left[0, r_{\mathrm{b}}\right]$

$J_{\mathrm{s}}(r)=\frac{1}{2} \frac{r_{\mathrm{s}}^{2}-r^{2}}{r}\left(\frac{2 y_{\mathrm{s}}}{r_{\mathrm{s}}} \dot{\mathrm{s}}_{\mathrm{s}}+\dot{y}_{\mathrm{s}}\right) \quad r=\left[r_{\mathrm{b}}, r_{\mathrm{s}}\right]$

with the boundary conditions:

$J_{\mathrm{gb}_{-} \mathrm{V}}(z=0)=0 \quad J_{\mathrm{gb}_{-} \mathrm{H}}(r=0)=0 \quad J_{\mathrm{s}}\left(r=r_{\mathrm{s}}\right)=0$

The dissipation rate per unit volume is given by:

$$
\begin{aligned}
& \bar{\Psi}\left(\dot{h}, \dot{y_{\mathrm{s}}}, \dot{r}_{\mathrm{s}}\right) \\
& \quad=\frac{1}{\mathrm{Vol}}\left[C_{2} \dot{h}^{2}+C_{1} \dot{y}_{\mathrm{s}}^{2}+\left(C_{1}\left(\frac{2 y_{\mathrm{s}}}{r_{\mathrm{s}}}\right)^{2}+C_{2}\left(\frac{2 h}{r_{\mathrm{s}}}\right)^{2}+C_{3}\right) \dot{r}_{\mathrm{s}}^{2}\right. \\
& \left.\quad+C_{1} \frac{4 y_{\mathrm{s}}}{r_{\mathrm{s}}} \dot{r}_{\mathrm{s}} \dot{y}_{\mathrm{s}}+C_{2} \frac{4 h}{r_{\mathrm{s}}} \dot{r}_{\mathrm{s}} \dot{h}\right]
\end{aligned}
$$

with

$$
\begin{aligned}
& C_{1}=\frac{\pi}{4 M_{\mathrm{s}} \Omega \delta_{\mathrm{s}}}\left(r_{\mathrm{s}}^{4} \ln \frac{r_{\mathrm{s}}}{r_{\mathrm{b}}}-r_{\mathrm{s}}^{2}\left(r_{\mathrm{s}}^{2}-r_{\mathrm{b}}^{2}\right)+\frac{r_{\mathrm{s}}^{4}-r_{\mathrm{b}}^{4}}{4}\right) \\
& C_{2}=\frac{\pi}{16 M_{\mathrm{gb}} \Omega \delta_{\mathrm{gb}} / 2} r_{\mathrm{b}}^{4} \\
& C_{3}=\frac{\pi}{3 M_{\mathrm{gb}} \Omega \delta_{\mathrm{gb}}} \sqrt{\frac{2 \pi}{\sqrt{3} N_{\mathrm{s}}}} \frac{1}{r_{\mathrm{s}}}\left(r_{\mathrm{b}}^{2} h^{3}+\left(r_{\mathrm{s}}^{2}-r_{\mathrm{b}}^{2}\right) y_{\mathrm{s}}^{3}\right)
\end{aligned}
$$

$\dot{G}$ is an explicit linear function of the rate of change of the geometrical variables and $\Psi$ is an explicit quadratic function. Evolution of the microstructure is dictated by the rates of change of the architecture that minimize the functional:

$\bar{\Pi}\left(\dot{h}, \dot{y}_{\mathrm{s}}, \dot{r}_{\mathrm{s}}\right)=\dot{\bar{G}}\left(\dot{h}, \dot{y}_{\mathrm{s}}, \dot{r}_{\mathrm{s}}\right)+\bar{\Psi}\left(\dot{h}, \dot{y}_{\mathrm{s}}, \dot{r}_{\mathrm{s}}\right)$

By time integration, using the fourth order Runge-Kutta method, the time evolution of the geometrical variables is obtained.

\section{Model Predictions}

Table 1 and 2 summarize the input data used for the geometry and material properties. The parameters describing the geometry are based on experimental observations. The splat thickness, $2 y_{\mathrm{s} 0}$, the size of the columnar grains, $r_{\mathrm{g} 0}$, and the distance between splat contacts, $2 r_{\mathrm{s} 0}$, are determined based on scanning electron microscope (SEM) micrographs. The open pore dimension, $2 y_{\mathrm{b}}$, is approximated based on the information on pore size distribution, given by $\mathrm{Hg}$-porosimetry experiments (Ref 18). Finally, the contact bridge radius, $r_{\mathrm{b}}$, is estimated based on SEM micrographs, porosity contribution of interlamellar pores, and surface area values of interlamellar pores (Ref 19). The surface diffusivity and activation energy are those reported for tetragonal $\mathrm{ZrO}_{2}-3$ mol\% $\mathrm{Y}_{2} \mathrm{O}_{3}$ (Ref 20), while grain boundary diffusivities are for tetragonal $14 \mathrm{CeO}_{2}-86\left(\mathrm{Zr}_{1-x} \mathrm{Hf}_{x}\right) \mathrm{O}_{2}$, with $x=0.02$ and 0.10 (Ref 21). $\Omega$ is the volume of the unit cell, calculated from lattice parameters obtained by $\mathrm{x}$-ray diffraction (XRD). $\delta_{\mathrm{s}}$ is taken as $\Omega^{1 / 3}$ and $\delta_{\mathrm{gb}}$ as $2 \Omega^{1 / 3}$

The model captures a number of experimentally observed sintering trends. Sintering causes pores to spherodize, the open pore dimension $y_{\mathrm{b}}$ to increase, the contact area $r_{\mathrm{b}}$ to increase and the total pore surface area to decrease (Fig. 4). Observations with small-angle neutron scattering have been reported (Ref 19), where it is shown that the mean opening dimensions of pores and microcracks increases and the crack and pore "penny" diameter decreases with heat treatment, as the pores and cracks evolve from a lenticular or plate-like shape, toward a more spherical geometry, with lower surface area.

\subsection{Sensitivity to Initial Pore Geometry}

Figure 5 compares experimental through-thickness shrinkage data, for low impurity $\mathrm{ZrO}_{2}-8$ wt. $\% \mathrm{Y}_{2} \mathrm{O}_{3}$ at $1400{ }^{\circ} \mathrm{C}$ (reported as AE1 in (Ref 18)), with model predictions. The observed fall-off in shrinkage rate with increasing time is correctly predicted. The behavior is sensitive to initial pore geometry. Predictions are shown for two pores of the same initial volume, but different initial pore surface area (see Table $1, \mathrm{CV}_{1}$ and $\mathrm{CV}_{2}$ ). Larger initial pore surface area leads to greater throughthickness shrinkage.

Figure 6 compares experimental surface area changes, measured using the Brunauer-Emmett-Teller (BET) adsorption isotherm ( $\operatorname{Ref} 23)$, with predicted surface area 


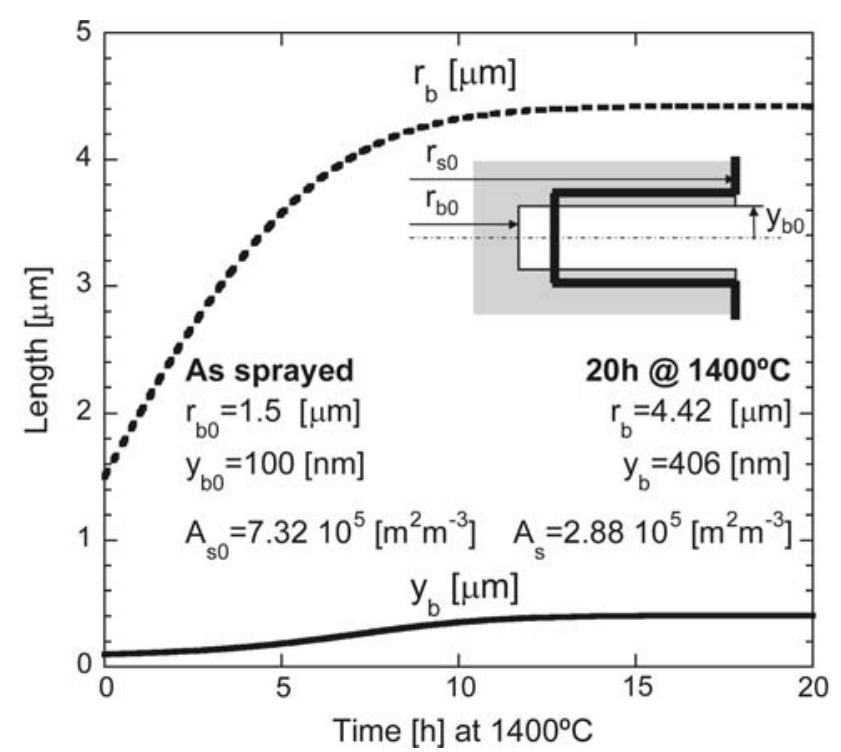

Fig. 4 Predicted changes with time of $r_{\mathrm{b}}$ and $y_{\mathrm{b}}$

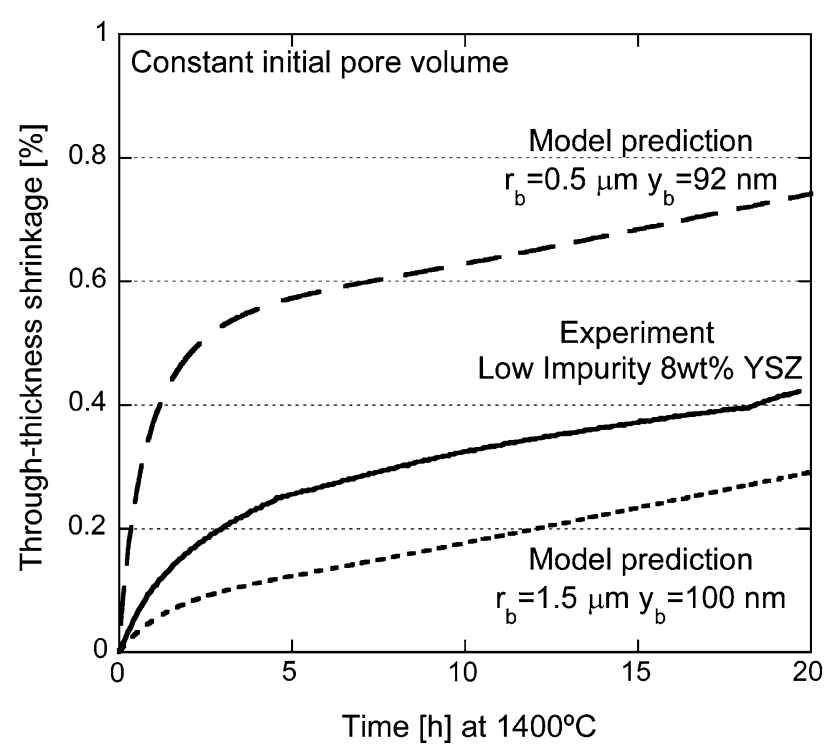

Fig. 5 Comparison between predicted and observed shrinkage for low impurity $\mathrm{ZrO}_{2}-8$ wt. $\% \mathrm{Y}_{2} \mathrm{O}_{3}$ at $1400{ }^{\circ} \mathrm{C}$ in the throughthickness direction

Table 1 Input geometry parameters

\begin{tabular}{|c|c|c|c|c|c|}
\hline & Unit & $\mathrm{CV}_{1}$ & $\mathrm{CV}_{2}$ & $\mathrm{CS}_{1}$ & $\mathbf{C S}_{2}$ \\
\hline \multicolumn{6}{|l|}{ Geometry parameters } \\
\hline$r_{\mathrm{b} 0}$ & $\mathrm{~m}$ & $1.50 \times 10^{-6}$ & $5.00 \times 10^{-7}$ & $1.00 \times 10^{-6}$ & $1.10 \times 10^{-6}$ \\
\hline$r_{\mathrm{s} 0}$ & $\mathrm{~m}$ & $5.00 \times 10^{-6}$ & $5.00 \times 10^{-6}$ & $5.00 \times 10^{-6}$ & $5.00 \times 10^{-6}$ \\
\hline$y_{\mathrm{b} 0}$ & $\mathrm{~m}$ & $1.00 \times 10^{-7}$ & $9.20 \times 10^{-8}$ & $2.50 \times 10^{-8}$ & $1.18 \times 10^{-7}$ \\
\hline$y_{\mathrm{s} 0}$ & $\mathrm{~m}$ & $1.25 \times 10^{-6}$ & $1.25 \times 10^{-6}$ & $1.25 \times 10^{-6}$ & $1.25 \times 10^{-6}$ \\
\hline$h$ & $\mathrm{~m}$ & $1.35 \times 10^{-6}$ & $1.34 \times 10^{-6}$ & $1.28 \times 10^{-6}$ & $1.37 \times 10^{-6}$ \\
\hline$r_{\mathrm{g} 0}$ & $\mathrm{~m}$ & $5.00 \times 10^{-7}$ & $5.00 \times 10^{-7}$ & $5.00 \times 10^{-7}$ & $5.00 \times 10^{-7}$ \\
\hline Pore volume & $\mathrm{m}^{3}$ & $7.15 \times 10^{-18}$ & $7.15 \times 10^{-18}$ & $1.88 \times 10^{-18}$ & $8.82 \times 10^{-18}$ \\
\hline Pore surface & $\mathrm{m}^{2}$ & $7.24 \times 10^{-11}$ & $7.80 \times 10^{-11}$ & $7.56 \times 10^{-11}$ & $7.56 \times 10^{-11}$ \\
\hline Porosity & $\%$ & 6.74 & 6.78 & 1.88 & 8.21 \\
\hline Specific surface area & $\mathrm{m}^{2} \mathrm{~m}^{-3}$ & $7.32 \times 10^{5}$ & $7.94 \times 10^{5}$ & $7.69 \times 10^{5}$ & $7.66 \times 10^{5}$ \\
\hline
\end{tabular}

Table 2 Input material properties

\begin{tabular}{|c|c|c|c|}
\hline \multicolumn{3}{|c|}{ Unit } & \multirow[t]{2}{*}{ Source } \\
\hline \multicolumn{3}{|c|}{ Material properties } & \\
\hline$D_{\mathrm{s} 0}$ & $\mathrm{~m}^{2} \mathrm{~s}^{-1}$ & $5.52 \times 10^{5}$ & $(\operatorname{Ref} 20)$ \\
\hline$Q_{s}$ & $\mathrm{~J} \mathrm{~mol}^{-1}$ & $5.31 \times 10^{5}$ & (Ref 20) \\
\hline$D_{\mathrm{gb} 0}$ & $\mathrm{~m}^{2} \mathrm{~s}^{-1}$ & $4.48 \times 10^{2}$ & (Ref 21) \\
\hline$Q_{\mathrm{gb}}$ & $\mathrm{J} \mathrm{mol}^{-1}$ & $5.06 \times 10^{5}$ & $(\operatorname{Ref} 21)$ \\
\hline$\gamma_{\mathrm{s}}$ & $\mathrm{J} \mathrm{m}^{-2}$ & 0.30 & (Ref 22) \\
\hline$\gamma_{\mathrm{gb}}$ & $\mathrm{J} \mathrm{m}^{-2}$ & 0.15 & \\
\hline$\Omega$ & $\mathrm{m}^{3}$ & $3.38 \times 10^{-29}$ & \\
\hline$\delta_{\mathrm{s}}$ & $\mathrm{m}$ & $3.23 \times 10^{-10}$ & \\
\hline$\delta_{\mathrm{gb}}$ & $\mathrm{m}$ & $6.47 \times 10^{-10}$ & \\
\hline
\end{tabular}

changes, for low impurity $\mathrm{ZrO}_{2}-8$ wt. $\% \mathrm{Y}_{2} \mathrm{O}_{3}$ at $1400{ }^{\circ} \mathrm{C}$ (reported as AE1 in (Ref 18)). The surface area reduction is also sensitive to initial pore geometry. Predictions are given for two pores of the same initial surface area (see Table $1, \mathrm{CS}_{1}$ and $\mathrm{CS}_{2}$ ). The final surface area and the rate of surface area reduction are very sensitive to the ratio of $y_{\mathrm{b}}$ to $r_{\mathrm{b}}$. Geometries with finer-open-pore dimension, $y_{\mathrm{b}}$, spherodize faster, and lead to greater pore surface area reductions.

\subsection{Sensitivity to Material Properties}

Sintering is sensitive to surface and grain boundary diffusivities. Surface diffusion has the effect of reducing the surface area, without causing densification. Grainboundary diffusion reduces both pore surface area and specimen volume. Through-thickness shrinkage (Fig. 7) and surface area reduction (Fig. 8) predictions are shown, for a given pore geometry, for surface and grain boundary diffusivites being doubled. An increase in grain boundary diffusivity generates a proportional increase in throughthickness shrinkage, whereas the pore surface area reduction remains almost unchanged. An increase in surface diffusivity, on the other hand, accelerates surface area reduction. Pore spherodization dominates, consuming the driving force for grain boundary diffusion and hence reducing the shrinkage.

The geometrical representation used in the present work has been employed previously to predict the throughthickness thermal conductivity (Ref 24). Figure 9 shows that the contact bridge to splat area ratio increases more rapidly with increasing surface diffusivity. Faster surface 


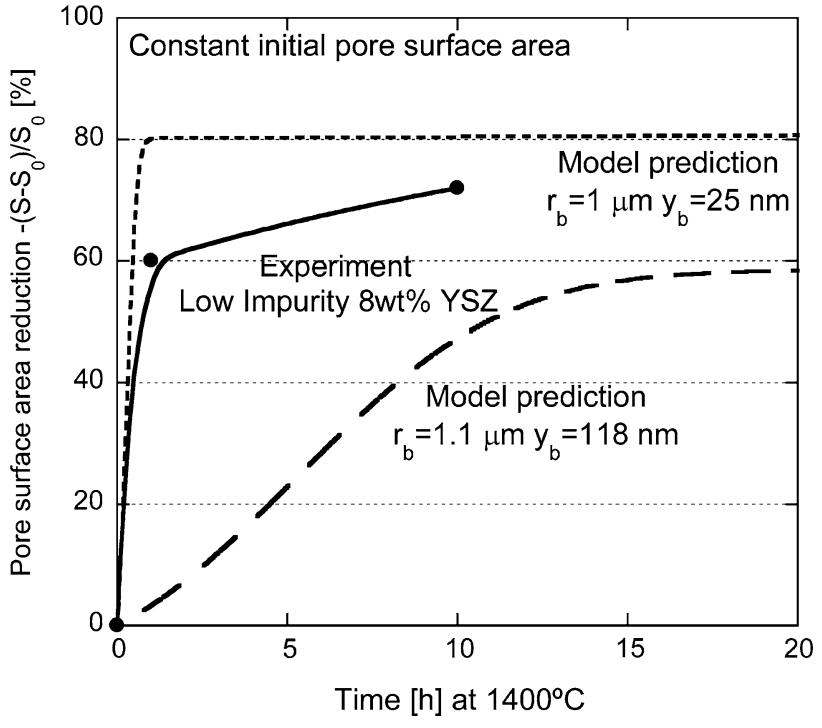

Fig. 6 Comparison between predicted and observed surface area reductions at $1400{ }^{\circ} \mathrm{C}$

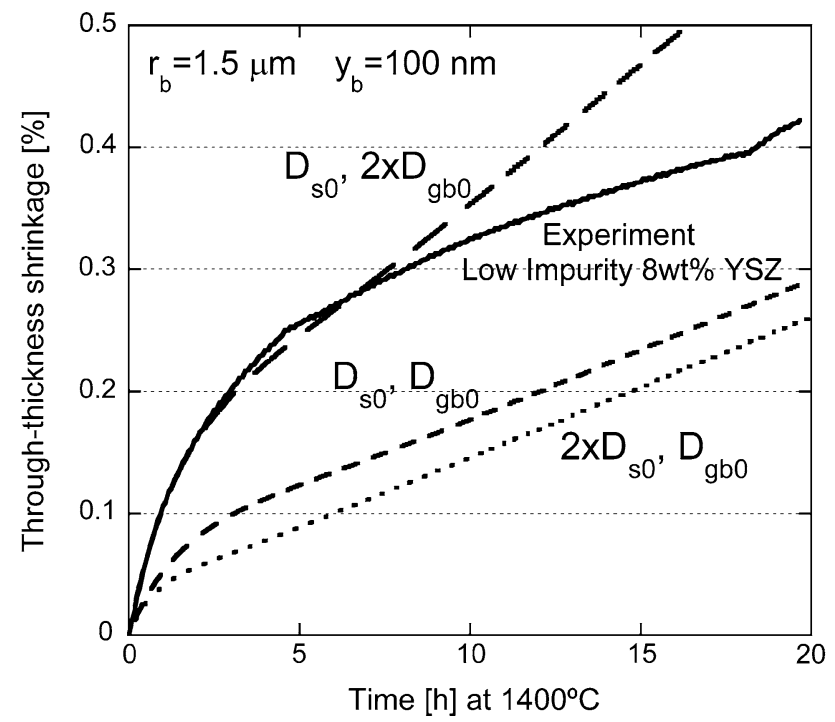

Fig. 7 Predicted shrinkage in the through-thickness direction, showing the effects of changing grain boundary and surface diffusivities

diffusion can thus accelerate the increase in thermal conductivity, while the rate of through-thickness shrinkage would be reduced. This indicates that the sintering behavior cannot be fully described by shrinkage measurements and complementary information is required, such as surface area reduction and changes in pore size distribution.

\subsection{Limitations of the Model}

The presented version of the model is based on intersplat pores of uniform size. In practice, a distribution of pore size would be more appropriate. This would also

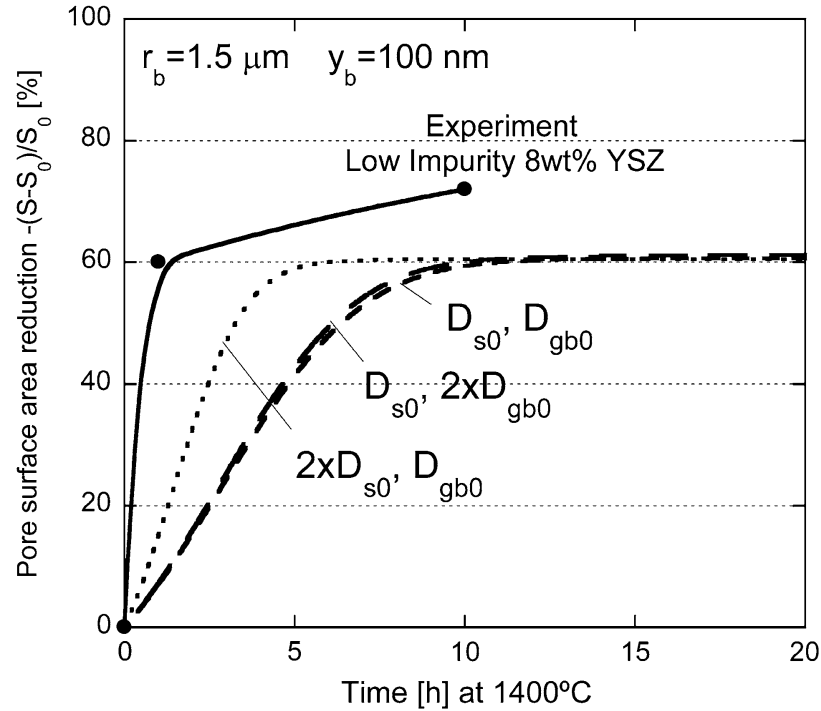

Fig. 8 Predicted changes in pore surface area at $1400{ }^{\circ} \mathrm{C}$, showing the effects of changing grain boundary and surface diffusivities

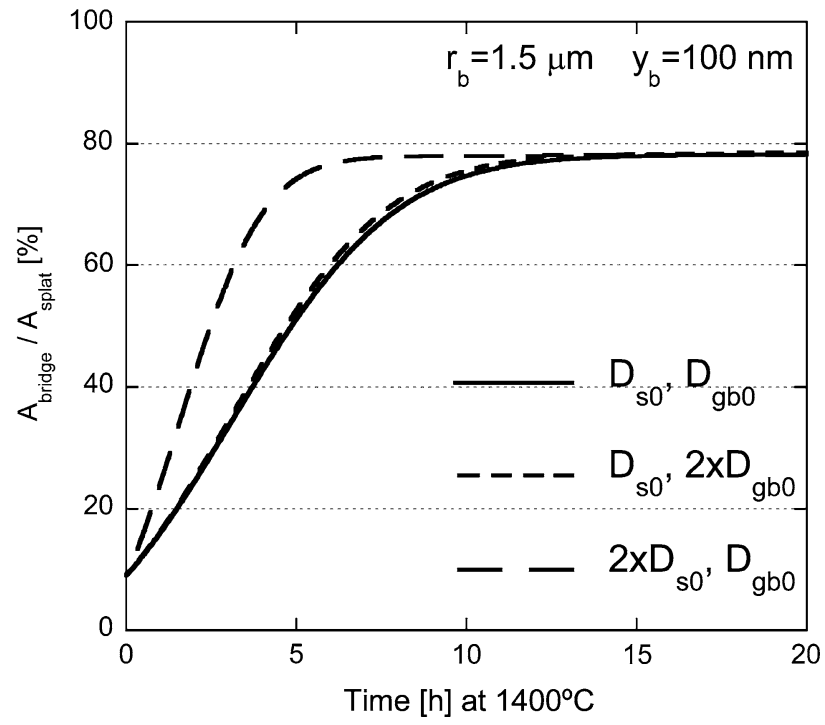

Fig. 9 Predicted changes in contact bridge area at $1400{ }^{\circ} \mathrm{C}$, showing the effects of changing grain boundary and surface diffusivities

account for intra-splat microcracks, with large surface to volume ratio, which can sinter quickly and may be the major contributors to surface area reduction. Other effects, such as grain growth, lattice diffusion, throughthickness thermal gradients, and stresses due to constraint on sintering and thermal expansion mismatch with the substrate, should all be introduced into a fully comprehensive model. This is currently under study. 


\section{Summary and Conclusions}

A sintering model for PS TBCs has been developed, based on the variational principle. Input data, covering geometry and material properties, are obtained from experimental studies and include no arbitrarily adjustable parameters. The model captures several well-established experimental trends and in general gives good agreement with experimental data and observations. The current model, however, is based on a simplified geometry and only accounts for uniform-sized, horizontal interlamellar pores. An improved version of the model will include a distribution of intersplat spacings, as well as vertical intrasplat microcracks. This will allow for more accurate predictions of shrinkage, both in the in-plane and thoughthickness direction, initial surface area values and its reduction with heat treatment, using the same set of geometrical parameters.

The model is, nevertheless, useful to predict sintering trends, depending on the initial pore architecture or material properties. The sensitivity analysis with respect to initial pore geometry shows that pores with larger initial surface area, but the same overall volume, lead to greater throughthickness shrinkage. Thus the initial porosity level does not dictate, in the proposed model, or even strongly influence, the sintering behavior. Moreover, pores with the same initial surface area, but different architecture $\left(y_{\mathrm{b}}\right.$ to $r_{\mathrm{b}}$ ratio) lead to differences in the rate of surface area reduction. Architectures with fine inter-splat spacings $\left(y_{\mathrm{b}}\right)$ sinter faster and exhibit more rapid pore surface area reduction.

The sensitivity of model predictions to material properties has also been studied. An increase in grain boundary diffusivity generates an approximately proportional increase in the rate of through-thickness shrinkage. Enhanced surface diffusivity, on the other hand, promotes pore spherodization and surface area reduction, consuming the driving force for grain boundary diffusion and hence cutting down the rate of through-thickness shrinkage. The model can also be used to predict the evolution of the inter-splat contact area, which can in turn be related to the throughthickness thermal conductivity, via a previously developed analytical model (Ref 24). The increase in the contact bridge area is predicted to accelerate with increasing surface diffusivity. Faster surface diffusion is thus expected to raise the rate of thermal conductivity increase, while reducing the rate of through-thickness shrinkage. Though, studying such effects experimentally presents challenges, since independently altering surface and grain boundary diffusivities is not a simple matter, but these predictions do have implications for controlling the sintering characteristics and may be of practical significance.

\section{Acknowledgments}

Financial support has come from a Basque Government scholarship (for AC), from EPSRC via Platform Grant and from Sulzer Metco (US) Inc. The authors are also grateful for extensive useful discussions with Sulzer Metco personnel, particularly Mitch Dorfman, Clive Britton, Keith Harrison, Liangde Xie and Jason Doesburg.

\section{References}

1. A. Needleman and J.R. Rice, Plastic Creep Flow Effects in the Diffusive Cavitation of Grain Boundaries, Acta Metall., 1980, 28, p 1315-1332

2. J. Pan and A.C.F. Cocks, A Numerical Technique for the Analysis of Coupled Surface and Grain-Boundary Diffusion, Acta Metall. Mater., 1995, 43(4), p 1395-1406

3. A.C.F. Cocks, Variational Principles, Numerical Schemes and Bounding Theorems for Deformation by Nabarro-Herring Creep, J. Mech. Phys. Solids, 1996, 44(9), p 1429-1452

4. A.C.F. Cocks and S.P.A. Gill, A Variational Approach to Two Dimensional Grain Growth - I. Theory, Acta Mater., 1996, 44(12), p 4765-4775

5. Z. Suo and W. Wang, Diffusive Void Bifurcation in Stressed Solid, J. Appl. Phys., 1994, 76(6), p 3410-3421

6. J. Svoboda, et al., Diffusion in Multi-Component Systems with No or Dense Sources and Sinks for Vacancies, Acta Mater., 2002, 50, p 1369-1381

7. R.G. Hutchinson, N.A. Fleck, and A.C.F. Cocks, A Sintering Model for Thermal Barrier Coatings, Acta Mater., 2006, 54(5), p 1297-1306

8. J. Svoboda and H. Riedel, Quasi-Equilibrium Sintering for Coupled Grain-Boundary and Surface Diffusion, Acta Metall. Mater., 1995, 43(2), p 499-506

9. B. Sun, Z. Suo, and A.C.F. Cocks, A Global Analysis of Structural Evolution in a Row of Grains, J. Mech. Phys. Solids, 1996, 44(4), p 559-581

10. F. Parhami, et al., A Model for the Sintering and Coarsening of Rows of Spherical Particles, Mech. Mater., 1999, 31, p 43-61

11. H.H. Yu and Z. Suo, An Axisymmetric Model of Pore-Grain Boundary Separation, J. Mech. Phys. Solids, 1999, 47, p 1131-1155

12. M. Saitou, Analysis of the Initial Stage of Sintering in Pure Materials by Surface Diffusion, Phil. Mag. Letts., 1999, 79(5), p 257-263

13. M. Saitou, Analysis of Sintering of Two Cylindrical Particles by Lattice or Grain Boundary Diffusion at the Initial Stage, Phil. Mag. Letts., 1999, 79(11), p 877-885

14. J. Pan, A.C.F. Cocks, and S. Kucherenko, Finite Element Formulation of Coupled Grain-Boundary and Surface Diffusion with Grain-Boundary Migration, Proc. Roy. Soc. Lond. A, 1997, 453, p 2161-2184

15. A.C.F. Cocks, S.P.A. Gill, and J. Pan, Modeling Microstructure Evolution in Engineering Materials, Adv. Appl. Mech., 1999, 36, p 81-162

16. J. Pan, Modelling Sintering at Different Length Scales, Int. Mater. Rev., 2003, 48(2), p 69-85

17. J. Pan and H.N. Ch'ng, Virtual Power Principle and Sintering Models at Particle Scale, Proceedings of the 4th International Conference on Science, Technology and Applications of Sintering, Grenoble, France, 2005

18. S. Paul, et al., Effects of Impurity Content on the Sintering Characteristics of Plasma Sprayed Zirconia, submitted to J. Therm. Spray Technol., 2007

19. A.J. Allen, et al., Microstructural Characterization of Yttria-Stabilized Zirconia Plasma-Sprayed Deposits using Multiple SmallAngle Neutron Scattering, Acta Mater., 2001, 49, p 1661-1675

20. A.M.J. Mayo, Zr Surface Diffusion in Tetragonal Yttria Stabilized Zirconia, J. Mater. Sci., 2000, 35, p 437-442

21. Y. Sakka, et al., Cation Interdiffusion and Phase Stability in Polycrystalline Tetragonal Ceria-Zirconia-Hafnia Solid Solution, J. Am. Cer. Soc., 1991, 74(10), p 2610-2614

22. R.N. German, Sintering Theory and Practice, 1st ed., John Wiley \& Sons, New York, 1996, p 534

23. S. Brunauer, P.H. Emmett, and E. Teller, Adsorption of Gases in Multimolecular Layers, J. Am. Chem. Soc., 1938, 60, p 309-319

24. I.O. Golosnoy, S.A. Tsipas, and T.W. Clyne, An Analytical Model for Simulation of Heat Flow in Plasma Sprayed Thermal Barrier Coatings, J. Therm. Spray Technol., 2005, 14(2), p 205-214

\section{.}

